\title{
PAGAMENTO INDEVIDO E ENRIQUECIMENTO SEM CAUSA
}

\author{
Carlos Alberto Dabus Maluf \\ Professor Associado do Departamento de Direito Civil da \\ Faculdade de Direito da Universidade de São Paulo
}

\begin{abstract}
Resumo:
O autor aborda, tomando como parâmetro as fontes romanas, o enriquecimento ilícito, traçando uma trajetória através da legislação estrangeira até a concepção atual no Direito Positivo brasileiro.

Contempla na matéria, ainda, o pagamento indevido desde a sua concepção objetiva e subjetiva, a retenção do pagamento indevido e o mesmo instituto no Projeto de Código Civil. Além do mais, o Projeto supre uma lacuna do Código Civil vigente, prevendo em seu texto o instituto do enriquecimento sem causa.
\end{abstract}

\begin{abstract}
:
The author broaches, taking the roman sources as parameter, the illegitimate enrichment, drawing a trajectory through the foreign legislation till the current conception in the brazilian Positive Right.

It also regards the subject with the improper payment, since its objective and subjetive conception, the retention of the improper payment and the same institute in the project of Civil Code. Add to that, the Project supplies a gap of the valid Civil Code, foreseeing in his text the institute of the causeless enrichment.
\end{abstract}

Unitermos: pagamento indevido; enriquecimento ilícito; enriquecimento sem causa.

Sumário:

1. Conceito e esboço histórico.

2. Legislação comparada.

3. Direito Positivo brasileiro.

4. Concepção objetiva e subjetiva do pagamento indevido.

5. O pagamento indevido que teve por objeto um imóvel.

6. Retenção do pagamento indevido.

7. O pagamento indevido no projeto de Código Civil.

8. Considerações finais.

9. Bibliografia. 
1. Conceito e esboço histórico

Trata-se de um instituto estreitamente ligado ao enriquecimento sem causa. Enquanto o nosso Código Civil silenciou a propósito do problema do enriquecimento sem causa, igual procedimento não teve quanto ao pagamento indevido, o qual foi minuciosamente regulado nos arts. 964 a 971.

Nas fontes romanas, o enriquecimento ilegítimo é geralmente indicado como lucro sine causa, que origina a obrigação de restituir. O que se locupleta com o alheio, está na posição do que toma alguma coisa por empréstimo: tem de restituíla. Para esse efeito foi criado o judicium stricti juris das conditiones.

As conditiones fundadas no enriquecimento injusto eram conhecidas pela designação geral de conditiones sine causa. O gênero, porém, comportava diversas espécies:

1. conditio indebiti era o direito de exigir o que se pagou indevidamente;

2. conditio causa data causa non secuta era o direito de reclamar o que se deu com intuito de alcançar um fim que se não realizou. Seria a hipótese do terceiro que forneceu o dote e que o pede de volta, por se não haver realizado o casamento;

3. conditio ob finitam causam - verifica-se, quando se pagou por uma razão que existia e que deixou de existir. Seria o exemplo do pai que presta pensão alimentícia à mulher, pelo filho do casal. Se o filho morrer, a razão de pagar não mais existirá. Assim, pode o cônjuge varão pleitear através dessa conditio as importâncias pagas depois do falecimento do menor.

Van Wetter em seu (Cours de Droit Romain, II $\S 480$ ) exemplifica com a entrega pelo devedor ao credor de um título pelo qual reconhece a dívida, que já tinha cessado de existir.

Demogue em (Obligations, III, 131), exemplifica com a continuação do pagamento do seguro depois de extinto.

4. conditio ob turpem vel injustam causam - cabia em Direito Romano para repetir o que se deu por uma causa honesta da parte de quem deu, mas desonesta ou injusta da parte de quem recebeu. Assim, o accipiens estava obrigado a restituir o que recebera por causa imoral. No mesmo sentido dispôs o Código Civil alemão. No nosso antigo Direito, as características eram as mesmas do Direito Romano. Como se lê em Teixeira de Freitas: "Compete a quem honestamente deu 
alguma coisa, por causa torpe ou injusta, contra quem a recebeu; pede que lh'a restitua com seus acessórios e rendimentos" E continua o grande mestre: "Se a causa era igualmente torpe ou injusta para quem deu, cessa esta ação". E como exemplo, o eminente civilista de nosso Direito anterior, lembra a hipótese de alguém dar dinheiro a uma meretriz para que esta ceda o uso de seu corpo. (notas a Correa Telles, na Doutrina das Ações, § 97).

5. conditio furtiva era a imaginada contra o ladrão.

Antes de adentrarmos no Direito Positivo brasileiro, faremos um rápido estudo de algumas legislações estrangeiras para um melhor esclarecimento da matéria.

\section{Legislação comparada}

O pagamento indevido foi considerado no Código Civil francês como um quase-contrato e, como tal, capitulado em lugar diverso do pagamento em geral (arts. 1.376 a 1.381). Quase-contrato é uma expressão incorreta com que os modernos procuram traduzir a idéia romana obligationes quasi ex contratu.

No Código Civil suíço figura o enriquecimento ilegítimo nos arts. 62 a 67 , como causa geradora de obrigações.

O Código Civil alemão nos apresenta a matéria como uma relação especial de direito e não como causa eficiente de obrigações em seus arts. 812 a 822.

O Código Civil italiano cuida do enriquecimento sem causa, nos arts. 2.033 a 2.042, tratando no Titolo VII - Del pagamento dell'indebito e no Titolo VIII - Dell'arrichimento senza causa. A orientação do atual Código italiano foi adotar uma concepção eclética; para certas situações toma por base um critério altamente objetivo (indebitum ex re); para outras exige o elemento subjetivo (indebitum ex persona). O primeiro caracteriza-se quando o accipiens aufere um enriquecimento em sentido absoluto, dada a inexistência do débito por exemplo caso de um pagamento haver sido realizado em conseqüência de um débito nulo. No indébito subjetivo, cumpre ao solvens demonstrar a sua incidência em erro, no ato do pagamento, o qual, se considera, subjetivamente indevido, verbi gratia, quando quem nada deve, paga a quem é credor tão-só em relação a uma outra pessoa. 
3. Direito Positivo brasileiro

O nosso Código Civil seguiu o sistema do Código Civil austríaco, que trata do pagamento de uma dívida inexistente, ao desenvolver a matéria do pagamento das obrigações. Aliás, Teixeira de Freitas, em seu Esboço já havia seguido o Código Civil austríaco. O Código Civil brasileiro considera a modalidade do enriquecimento sem causa legítima, que reveste o aspecto do pagamento indevido, subordinado ao título do próprio pagamento. Assim sendo, toda a matéria do pagamento deve subordinar-se ao mesmo título do Código, quer se trate do que se pagou devidamente, quer se trate do indevido, contra o que se insurge o eminente obrigacionista Orozimbo Nonato.

O Código Civil brasileiro não conhece uma doutrina dos quasecontratos, nem considerou o enriquecimento ilícito como figura especial de obrigação.

\section{Concepção objetiva e sụbjetiva do pagamento indevido}

Aqui, devemos considerar dois aspectos: a. alguns grupos de legislação o regulam com o caráter objetivo; b. outros lhe dão o aspecto predominantemente subjetivo. Quer isto dizer: enquanto uns tomam o pagamento indevido como se operando ex re, caracterizando-se pelo simples fato de se haver pago o indevido, outros, ao contrário, exigem um elemento subjetivo - o erro do solvens. No Direito Romano, prevalecia o critério subjetivo. Qual a posição assumida pelo nosso Direito Positivo em face da concepção do pagamento indevido?

É evidente a sua inspiração nos princípios romanos. A conditio in debiti romana se traduziu no nosso Direito, pela combinação dos arts. 964 e 965 do Código Civil: "Todo aquele que recebeu o que the não era devido fica obrigado a restituir" (art. 964), mas "ao que voluntariamente pagou o indevido incumbe a prova de tê-lo feito por erro" (art. 965).

Como idéia complementar a lei considera indevido o que se recebeu por "divida condicional, antes de cumprida a condição" (alínea do art. 964 do Código Civil).

Vejamos agora a diferença entre prazo e condição. Para o grande Bevilacqua, em seus Comentários, o prazo supõe uma obrigação já existente, apenas o seu cumprimento é demorado por algum tempo. E continua o mestre Clóvis: " $A$ 
obrigação condicional, porém, ainda não existe. Cumprí-la é dar o que não é devido."

Tratando do que voluntariamente pagou, para mandar provar o erro que viciou a vontade, a lei o faz expressamente pela necessidade de examinar o pagamento em face de sua causa a obrigação a que solve, circunstância que impõe abordar o erro como espécie particular entre os defeitos dos atos jurídicos. $\mathrm{O}$ erro impõe que se estude o nexo entre o pagamento e a obrigação pressuposta, e isto caracteriza o indébito.

Baudry Lacantinerie et Barde acham rigorosa a exigência da prova do erro para caracterizar o pagamento indébito, entendendo que a ausência completa de dívida, mesmo natural, importa a presunção de erro (Traité, IV, 2.836, I). Do exposto fica claro que a eqüidade se norteia pela noção do erro para conceituar a conditio indebiti, e regular o direito à repetição. Assim entende Demogue em (Obligation, III, 107):

"Si tout paiement indu doit donner lieu à repetition, encore faut-il, qu'il n'y ait pas un principe plus fort que le droit à repetition pour s'y opposer"

Desde que para repetir, o art. 965 exige a prova do erro do que voluntariamente pagou o indevido, fica implicitamente dispensado desta prova aquele que involuntariamente pagou: pois lhe assiste o art. 964 que obriga a restituir, todo aquele que recebeu o que lhe não era devido. Assim, se houve coação, deve o legislador negar eficácia a um ato que se consumou na violência, quer seja esta do accipiens ou de terceiros. Se o solvens foi obrigado a pagar violentamente, sua vontade livre não se manifestou, e por este motivo tem direito à repetição.

Agora, se o solvens pagou voluntariamente, o que sabia não dever, entende-se que este ato representa uma liberalidade.

Com efeito. A lei ampara o que paga por erro, impedindo dessa maneira e por uma razão de eqüidade, seu injusto empobrecimento. No mesmo sentido é o pensamento de nossos tribunais, (Revista dos Tribunais 218/220):

"Tendo pago voluntariamente, cumpria ao autor provar havê-lo feito por erro"

É possível ainda, que o solvens prove o dolo ou a simulação do accipiens, que se enquadram dentro dos defeitos dos atos jurídicos, persuadindo-o a 
fazer aquele pagamento. Nesses casos, e em outros semelhantes, basta que se verifique o vício como causador do pagamento, para se decretar a anulação do negócio, segundo o princípio geral do art. 147 do Código Civil.

Assim, qualquer que seja o erro, de direito, de fato, escusável ou-não, é ele capaz de levar à repetição do indébito. Alguns autores, em pequeno número, procuraram, porém, excluir o erro de direito como elemento integrante da repetição do indevido, tão-somente obedecendo a um critério provindo do Direito Romano. Este ponto de vista foi contestado por M.I. Carvalho de Mendonça em (Obrigações, I, n. 275). Aliás o grande Serpa Lopes em seu Curso de Direito Civil, também se manifesta favoravelmente à existência do erro de direito (v. 1, n. 277, pp. 434-435). $\mathrm{Na}$ verdade, é este o critério seguido predominantemente entre os doutrinadores e nas legislações. Dentro de nossa jurisprudência, podemos citar, (Revista dos Tribunais 302/561):

"Não-só o erro de fato, mas igualmente o de direito, pode ser invocado como fundamento da conditio indebiti"

5. O pagamento indevido que teve por objeto um imóvel

É possivel que o pagamento indevido se tenha efetuado pela dação de um imóvel. Fundamentalmente, isto em nada muda os princípios dos arts. 964 e 965 do Código Civil. Assim, o solvens, que transferiu ao accipiens imóvel em pagamento indevido, pode conseguí-lo de volta, se provar que pagou por erro. Solvens e accipiens voltam ao estado anterior em que se encontravam, desfazendo-se em conseqüência o negócio.

Aqui temos duas hipóteses a considerar:

1. Se o accipiens agiu sem malícia e recebeu o pagamento acreditando ser o mesmo devido é tratado como possuidor de boa-fé. Isto significa que: a. tem direito aos frutos percebidos; b. não-responde pela deterioração ou perda da coisa, a que não deu causa; c. recebe indenização pelas benfeitorias úteis e necessárias, podendo levantar as voluptuárias; d. cabe-lhe direito de retenção pelo valor daquelas.

2. Se o accipiens agiu com malícia, responde pelos danos causados, como possuidor de má-fé. 
Essas hipóteses se encontram reguladas pelo Código Civil, em seus arts. 510 a 519 e 966.

Contudo, pode acontecer que, tendo recebido um imóvel em pagamento, o accipiens o tenha alienado, a título oneroso ou gratuito, a terceiro de boa-fé ou má-fé. Nesse caso, qual é a solução dada pela lei?

a. pagamento indevido, efetuado pela dação de um imóvel, a seguir alienado a título oneroso pelo accipiens, estando todas as partes de boa-fé Nessa hipótese, não defere a lei ao solvens, o direito de reivindicar a coisa. Pelo contrário, compete-lhe absorver o prejuízo, só lhe restando a prerrogativa da ação regressiva contra o accipiens. A responsabilidade do alienante pela entrega do preço que recebeu se justifica, pois, do contrário, estaria a se locupletar ilicitamente. Seria, em resumo, um enriquecimento sem causa.

Aliás Silvio Rodrigues em seu Direito Civil, (v. 2), com sua habitual clareza e precisão assim entende:

"Há dois interesses colidentes em jogo. De um lado, o interesse do solvens que, havendo transferido por erro o domínio de certo bem, procura reintegrá-lo em seu patrimônio, de onde, aliás, não devia ter saído. De outro lado, encontra-se o interesse do terceiro de boa-fé, que havendo adquirido o imóvel de quem aparentemente era seu dono, agiu como agiria o prudente pai de família, sendo induzido ao negócio por circunstâncias que induziriam qualquer pessoa."

E mais adiante na mesma obra continua o mestre:

"Qual dos dois interesses merecerá a proteção da lei? Evidentemente o do terceiro de boa-fé, que nada tendo a se censurar, que não havendo nem sequer indiretamente colaborado para aquela situação de fato, se encontraria, caso contrário, na iminência de sofrer um prejuizo inteiramente injustificado. A solução da lei atua no sentido de reforçar a confiança nas relações negociais, que se querer firmes e estáveis" 
Clóvis Bevilacqua diz em seus Comentários que a doutrina do Código Civil brasileiro neste art. 968, não foi a mais justa. Ainda Bevilacqua em seu Direito das Obrigações (§ 41, p. 159, $2^{\mathrm{a}}$ edição) escreveu:

"Havendo o accipiente, de boa-fé, alienado o imóvel, que lhe foi dado em pagamento indevido, terá o solvente direito de reivindicá-lo do poder de quem quer que o detenha. É uma consequiencia rigorosa dos principios, porque a propriedade se não extinguiu com o estabelecimento da obrigação putativa"

Como vimos, Clóvis ressaltou e com ênfase o direito de seqüela, que deve sempre a nosso ver, ser protegido pelo Direito.

A questão não é pacífica. O professor Washington de Barros Monteiro em seu precioso Curso de Direito Civil (Direito das Obrigações - $1^{\mathrm{a}}$ parte, p. 278, $9^{\mathrm{a}}$ ediçạo) assim entende:

"Segundo pensamos, o citado art. 968, aplica-se exclusivamente à hipótese de pagamento indevido, não podendo estendê-lo às aquisições a non domino, a título oneroso, ainda que de boa-fé o terceiro adquirente. Nessa hipótese, o verdadeiro proprietário tem direito à reivindicação, e não apenas a ação de indenização contra o alienante. Mas essa questão continua sendo ainda das mais controvertidas em nosso direito".

Em sentido contrário a Barros Monteiro, encontra-se Serpa Lopes, que em seu Curso de Direito Civil, (v. 5, p. 119), em nota de rodapé n. 32, assim expõe:

"Quanto ao nosso ponto de vista em tôrno desse problema e já exposto no Tratado dos Registros Públicos (v. $l^{\circ}$, p. 48), cumpre-nos esclarecer que o que ali deixamos dito foi que o art. 968 igualmente para nós era circunscrito às aquisições feitas por fôrça de um pagamento indevido sem qualquer conexão com o problema da aquisição a non domino. A referência ali feita ao art. 968 foi para que o seu texto servisse de adminículo à tese do valor probante do Registro 
imobiliário, suprindo as deficiências dos dispositivos legais concernentes à matéria. Tal foi o nosso pensamento fundamental nesse assunto. Com o defendermos uma aplicação analógica de modo nenhum quer dizer que sustentássemos uma extensão do preceito às aquisições a non domino, de modo que o supracitado dispositivo continua para nós com o mesmo aspecto $e$ finalidade com que foi inserto no Código Civil"

b. alienação a título gratuito e de boa-fé, pelo accipiens, do imóvel recebido indevidamente - Neste caso o conflito entre o interesse do terceiro adquirente e o do solvens se propõe em termos diversos, porque, enquanto o solvens procura evitar um prejuízo, o terceiro procura alcançar um lucro, isto é, quer obter um aumento de seu patrimônio.

Neste particular é procedente a lição de Jorge Americano em sua preciosa monografia Ensaio sobre o enriquecimento sem causa (Livraria Acadêmica, 1933) à p. 28:

"Em tal hipótese, como sucede em relação à ação pauliana, compara a situação do solvens que empobrece, com a do terceiro que enriquece a título gratuito, e manda reduzir-se o patrimônio 'in quantum locupletior factus', (art. 968, § único). Não inquire-se o adquirente estava de boa ou de má-fé. Anula a aquisição em homenagem ao princípio universal de eqüidade que prefere o que 'certat de damno vitando' ao 'que certat de lucro captando'. A situação do adquirente em boa-fé a título gratuito comparada ao solvens indebiti revela uma superioridade iniqua daquele sobre este, de modo que a eqüidade intervém no sentido da fórmula do Código Civil português.

Tanto o adquirente em boa-fé exerce o próprio direito quando adquire a título gratuito, como o exerce o solvens indebiti quando restaura a situação patrimonial empobrecida pelo pagamento indevido; mas o primeiro procura interesses quando adquire a título gratuito, ao 
passo que o segundo apenas evita prejuizos, quando reivindica." (grifos nossos)

Com efeito. Concordamos com Jorge Americano nessa sua interpretação, e podemos dizer ainda que foi feliz o legislador ao determinar essa norma no $\S$ único do art. 968 do Código Civil. Assim, ao mesmo tempo que a lei não-permite ação reivindicatória contra o adquirente de boa-fé, e a título oneroso, ela a defere contra o adquirente a título gratuito, ainda que imbuído de boa-fé.

A doutrina é unânime neste aspecto. Orlando Gomes em suas Obrigações, ( $3^{\mathrm{a}}$ edição, p. 288) assim se expressa:

"Na hipótese de ter alienado o imóvel, de boa ou de má-fé a título gratuito, fica obrigado, na ação de tutela da propriedade, a assistir a quem entregou por erro de pagamento, seja na de retificação do registro, seja na de reivindicação. Não importa que o terceiro adquirente tenha procedido de boa-fé. Em qualquer circunstância, a gratuidade da alienação justifica a ação do proprietário verdadeiro em defesa do seu direito real. Não é válida, por outras palavras, a alienação 'a non domino', a título gratuito"

c. alienação pelo accipiens, a título oneroso, a terceiro de má-fé, do imóvel recebido indevidamente Também nessa hipótese, é permitida a reivindicação do imóvel, quando o terceiro adquirente agiu de má-fé. É perfeitamente compreensivel que o adquirente sofra a perda da propriedade, eis que lhe falta a justificativa da boa-fé. Aliás, não há razão alguma para que a lei proteja seu interesse dada a torpeza de seu proceder.

Se o accipiens agiu de má-fé uma dupla solução se apresenta, conforme tenha ou-não o terceiro agido de boa-fé. Se o accipiens e o terceiro agiram de má-fé, o solvens também pode reivindicar o imóvel. No entanto, se o accipiens estava de má-fé e o terceiro adquirente imbuído de boa-fé, em respeito a este último a lei determina que o negócio deve ser mantido.

Pela leitura do caput do art. 968, pode-se concluir que, a lei não dando a prerrogativa de reivindicação a quem pagou indevidamente, confere-lhe o direito de pleitear de quem torpemente recebeu o pagamento, não-somente o preço recebido, mas também as perdas e danos pela alienação do imóvel. 
6. Retenção do pagamento indevido

Como diz o professor Caio Mário da Silva Pereira em suas Instituições de Direito Civil, (v. II, $3^{\mathrm{a}}$ edição, p. 252), "nem sempre, porém, o pagamento indevido é repetível. A lei atende a razão de eqüidade e é que inspira a restituição. Portanto, onde falta este fundamento, descabe a repetitio" E continua o eminente civilista: "às vezes a eqüidade mesma é que alicerça a obrigação do solvens; outras vezes é a sua conduta que ressai incompativel com qualquer proteção, e por isto a repele; outras ainda é a situação juridica do accipiens que a desaconselha."

O art. 969 do Código Civil em sua primeira parte assim dispõe:

"Fica isento de restituir pagamento indevido aquele que, recebendo-o por conta de divida verdadeira, inutilizou o titulo, deixou prescrever a ação, ou abriu mão das garantias, que asseguravam seu direito"

$\mathrm{Na}$ sua segunda parte, assim reza o artigo: "mas o que pagou, dispõe de ação regressiva contra o verdadeiro devedor e seu fiador"

Interpretando o artigo, podemos dizer que o credor ao receber pagamento de outra pessoa, que não seu devedor, o fez por conta de dívida verdadeira e inutilizou o título que a representava, não pode ser compelido a repetir. Em outras palavras, não precisa devolver o pagamento. $\mathrm{Na}$ verdade, recebeu o indevido, pois quem pagou nada lhe devia.

Inutilizando o título, privou-se o accipiens da prova de exercer o seu direito, perdendo, quiçá, a possibilidade de o fazer valer contra o verdadeiro devedor. Entre o interesse do solvens, que pagou por erro e o do accipiens, cujo comportamento não deve ser condenado, preferiu a lei defender os interesses do último, permitindo-lhe conservar o que recebeu.

Para a hipótese de prescrição ou de perecimento das garantias a solução se apóia no mesmo argumento. Por conseguinte, se extintas as garantias da dívida, ou após consumada a prescrição, o solvens demonstra ser indevido o pagamento, não é mais devida a repetição.

Mas, como não seria justo que se prejudicasse o solvens, a lei the confere ação regressiva contra o verdadeiro devedor e seu fiador, para haver de volta a importância que dispendeu, ou ressarcir-se dos prejuizos sofridos. Esta ação é de in 
rem verso, pois independe de qualquer relação entre as partes e se estriba no enriquecimento indevido do réu.

Nesse particular o Código Civil italiano ampara melhor o solvens, pois Ihe concede sub-rogação nos direitos do accipiens, em seu art. 2.036, segunda parte, quando diz:

"Quando la ripetizione non è ammessa, colui che ha pagato subentra nei diritti del creditore".

Vejamos agora, o art. 970 do Código Civil. Este dispositivo assim é disposto:

"Não se pode repetir o que se pagou para solver divida prescrita, ou cumprir obrigação natural"

O Código Civil neste artigo seguiu a orientação de outras legislações como, por exemplo, o art. 1.235 do Código Civil francês, que assim reza:

"Tout payement suppose une dette: ce qui a été payé sans être dî, est sujet à répétition. La répétition n'est pas admise à l'égard des obligations naturelles qui ont étévolontairement acquittées."

Obrigação natural É aquela desprovida de sanção, pois o devedor cumpre se quiser. Caracteriza-se por ser suscetível de execução voluntária somente, sem que possa o devedor ser forçado a cumpri-la judicialmente.

Lacerda de Almeida, o grande civilista pátrio, em sua obra Obrigações, de 1897, à p. 7 assim entende:

"Segundo a sua maior ou menor eficácia classificamse as obrigações naturais em duas grandes categorias, dependendo a maior ou menor eficácia delas de ser o fato donde se originam tolerado ou reprovado pela lei civil. As obrigações fundadas em causa legalmente reprovada só tem um efeito - impedirem a repetição a título de indébito (repetitio indebiti) e garantirem conseguintemente a retenção do pagamento recebido (soluti retentio). As obrigações ao contrário que 
assentam em causa tolerada são suscetiveis de todos os efeitos juridicos, menos o direito de ação."

Sílvio Rodrigues, em seu Direito Civil, v. 2, à p. 203, nas notas n. 201, transcreve a opinião de Colin e Capitant em "Cours": II, p. 64:

"A obrigação natural é uma obrigação despida de sanção. O credor não pode executar o devedor. Este último fica, portanto, livre de cumprí-la ou não; é negócio entre ele e sua consciência. Apenas, uma vez que ele voluntariamente reconheceu a existencia de sua obrigação, ela se transforma em obrigação civil perfeita $e$, desde então, o pagamento que faz ao credor é válido e não pode ser repetido"

A obrigação natural trata-se evidententemente, de um instituto suigeneris, mais aceito dentro da moral do que propriamente no direito.

O Código Civil não-incluiu a dívida prescrita entre as obrigações naturais, tanto que diferencia uma da outra, no art. 970.

Bevilacqua, em seus Comentários a esse artigo entende ser incabível a distinção, e assim se expressa:

"Denomina-se obrigações naturais as que não conferem direito de exigir o seu cumprimento, as desprovidas de ação, como: as prescritas, as de jogo $e$ apostas, em geral, as que consistem no cumprimento de um dever moral"

Mazeaud, Mazeaud e Mazeaud em suas Leçons de Droit Civil Premier Volume Obligations Théorie Génerale - Tome Deuxième, p. 703 assim entendem:

"L'obligation naturelle n'est pas susceptible d'exécution forcée, mais elle existe et constitue la cause valable d'un paiement. Le paiement d'une obligation naturelle n'est donc pas un paiement de l'indu, et ne permet pas au solvens de réclamer la restitution". 
O Anteprojeto do professor Caio Mário da Silva Pereira desprezou a expressão obrigação natural, assim dispondo o art. 145 desse Anteprojeto:

"Não se pode repetir o pagamento feito para solver dívida prescrita ou obrigação judicialmente inexigível"

Concluindo, quem paga obrigação natural não-pratica uma liberalidade, mas cumpre dever a que, em seu foro interior, se achava preso.

Finalmente, para encerrarmos essa exposição sobre o pagamento indevido, vamos analisar o art. 971 do Código Civil.

Dispõe esse artigo in verbis:

"Não terá direito à repetição aquele que deu alguma coisa para obter fim ilicito, imoral ou proibido por lei"

Portanto, se o pagamento se efetuou com o escopo de alcançar fim ilícito ou imoral, não tem o solvens direito de repetí-lo.

O Código Civil italiano focaliza a matéria em seu art. 2.035, que assim reza:

"Chi ha eseguito una prestazione per uno scopo che, anche da parte sua, costituisca offesa al buon costume non può ripetere quanto ha pagato."

É a aplicação do princípio "nemo auditur propriam turpitudinem allegans", isto é, ninguém pode ser ouvido alegando a sua própria torpeza.

Os irmãos Mazeuad, na obra citada, à p. 704, assim se manifesta sobre a regra nemo auditur:

"Nul n'est écouté lorqu'il se prévaut de son immoralité. La personne qui a passé un contrat immoral, donc nul, et qui a exécuté sa prestation, ne peut réclamer la restitution; lui premettre de demander la repétition de l'indu, serait lui permettre de se prévaloir de sa prope immoralité: in pari causa turpitudinis cessat repetitio. Les tribunaux font jouere cette règle dans les matières ayant trait à la morale sexuelle, particulièrement quant aux contrats portant sur les maisons de tolérance" 
Os princípios que genericamente dão lugar à conditio ob turpem causam, aplicam-se à espécie de jogo e da aposta (art. 1.477 do Código Civil). Embora se possa negar a causa do jogo ou aposta seja propriamente torpe, força é convir em que seja injurídica, e portanto injusta. Assim, na expressão de Ferrara em seu Negocio lllecito, n. 122, edição de 1914, que "aliás considera o jogo causa torpe, a prestação voluntária de quem se encontrava em uma relação de débito, ética ou socialmente reconhecida, vale como pagamento"

Como já mencionamos anteriormente, Bevilacqua, em seus Comentários, considera o jogo como espécie de obrigação natural.

Podemos dizer que o princípio do repúdio ao dolo tanto como o da simples eqüidade, impõe esta conseqüencia do art. 971 do Código Civil. Nosso Código, não encarou o problema da regra "nemo auditur". expressamente em seu texto, como o fizeram outros alienígenas, por exemplo, o suíço das Obrigações, o alemão e o austríaco. Contudo, em algumas de suas disposições parece ter consagrado a parêmia latina, como nas hipóteses dos arts. 97 (dolo), 104 (simulação) e 971 que acabamos de analisar.

7 O pagamento indevido no projeto de Código Civil

No projeto do professor Miguel Reale, o pagamento indevido é tratado nos arts. 878 a 885 . Se fizermos uma comparação entre o Código vigente e o Projeto, iremos verificar que este seguiu as normas e diretrizes daquele, mudando muito pouco ou quase nada as disposições dos artigos.

Com efeito. Chega-se à conclusão de que o legislador de 1916 agiu com muita cautela ao elaborar os artigos referentes ao pagamento indevido, adotando a concepção subjetiva do Direito Romano, no que foi seguido pelo Projeto, ora em discussão na capital da República, e que por isso merece nosso aplauso.

\section{Considerações finais}

Se nosso Código Civil não dispôs expressamente sobre o enriquecimento sem causa, apesar de tê-lo feito implicitamente, como nos casos dos 
arts. 513, 515, 541, 613, 964, 1.332, 1.339, dentre outros, nosso Projeto do professor Reale, consagrou a matéria em seus arts. 886 a 888.

Assim dispõe o art. 886 do Projeto: "Aquele que, sem justa causa, se enriquecer à custa de outrém, será obrigado a restituir o indevidamente auferido, feita a atualização dos valores monetários."

Parágrafo único - "Se o enriquecimento tiver por objeto uma coisa determinada, quem a recebeu é obrigado a restituí-la. Se a coisa não mais subsistir, a restituição se fará pelo valor do bem na época em que foi exigido"

Entendemos procedente a disposição expressa do enriquecimento sem causa dentro de nossa lei civil, pois, assim, não ficaremos adstritos às interpretações dos doutrinadores e da jurisprudência sobre tão-discutida matéria.

Aliás, o professor Agostinho Alvim, num magnífico artigo publicado na Revista dos Tribunais, v. 259, p. 3 e ss., assim se expressava:

"Por outro lado, é inquestionável que a condenação do enriquecimento injustificado é princípio geral de direito, porque, com maior ou menor extensão, ela tem sido recomendada por todos os sistemas, no tempo e no espaço".

Finalmente, para terminar, vamos transcrever a oportuna lição de Orlando Gomes, em suas Obrigações, $3^{\mathrm{a}}$ edição, 1972, no que diz respeito ao enriquecimento ilícito. Diz o mestre à p. 289 de sua obra brilhante:

"Há enriquecimento ilícito quando alguém, a expensas de outrem, obtém vantagem patrimonial sem causa, isto é, sem que a tal vantagem se funde em dispositivo de lei ou em negócio jurídico anterior. São necessários os seguintes elementos: a. o enriquecimento de alguém; b. o empobrecimento de outrem; c. o nexo de causalidade entre o enriquecimento $e \quad o$ empobrecimento; $d$. a falta de causa injusta"

Como se pode notar, o enriquecimento sem causa está intimamente ligado ao instituto do pagamento indevido e o Projeto veio suprir uma lacuna existente na lei. Ficaremos, pois, na expectativa de que um dia o enriquecimento sem 
causa passe a fazer parte integrante de nosso Código Civil, para dar mais proteção e estabilidade no Direito das Obrigações.

São Paulo, janeiro de 1998.

9. Bibliografia

ALMEIDA, Francisco de Paula Lacerda de. Obrigações, Livraria Cruz Coutinho, 1897.

ALVIM, Agostinho Neves de Arruda. Artigo publicado na Revista dos Tribunais, v. 259.

AMERICANO, Jorge. Ensaio sobre o enriquecimento sem causa. Livraria Acadêmica, 1933.

AUBRY et RAU. Cours de Droit Civil Français, 4 e 5 me. éd. Marchal, Paris, 1917.

BAUDRY Lacantinerie et Barde. Tratt. Teor. prat. di Diritto Civile, delle Obbligazioni, Vallardi, Milano, 1915.

BEVILACQUA, Clóvis. Código Civil dos Estados Unidos do Brasil, $8^{a}$ edição, Livraria Francisco Alves, v. IV, 1950.

Direito das Obrigações, $7^{\mathrm{a}}$ edição, Livraria Francisco Alves, 1950.

BRECCIA, Umberto. "La buona fede nel pagamento dell'indebito" artigo publicado na Rivista di Diritto Civile, Parte Prima, Cedam Casa Editrice Dott. Antonio Milani, Padova, anno XX, 1974.

COLIN et CAPITANT. Cours Elém. de Droit Civil Français, Paris, Dalloz, 1935.

DEMOGUE, René. Traité des Obligations en Général, Paris, Rousseau, 1923.

FERREIRA, José G. Valle. Enriquecimento sem causa, Belo Horizonte, Imprensa Oficial, 1949.

GOMES, Orlando. Obrigações, $3^{\mathrm{a}}$ edição, Editora Forense, 1972.

LOPES, Miguel Maria Serpa. Curso de Direito Civil, Rio de Janeiro, Freitas Bastos, v. V. 1961.

MAZEAUD, Henri, Léon \& Jean. Leçons de Droit Civil, Tome Deuxième, Cinquiême Édition, Premier Volume Obligations, Théorie Générale, Paris, Éditions Montchrestien, 1973.

MENDONÇA, Manuel Ignácio Carvalho de. Doutrina e Prática das Obrigações, $4^{\mathrm{a}}$ edição, Revista Forense, 1956. 
MONTEIRO, Washington de Barros. Curso de Direito Civil, $4^{\circ}$ v., Direito das Obrigações, $1^{\text {a }}$ parte, $9^{\mathrm{a}}$ edição, Saraiva, 1973.

NONATO, Orozimbo. Curso de Obrigações, Rio de Janeiro, Editora Forense.

PEREIRA, Caio Mário Silva. "Instituições de Direito Civil", v. II, Teoria Geral das

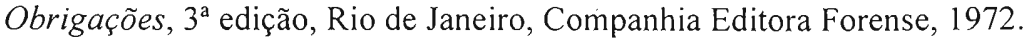

RÁO, Vicente. Parecer publicado na Revista Forense, v. 183, maio/junho, 1959.

RESCIGNO, Pietro. "Ripetizione dell'indebito", verbato publicado no Novissimo Digesto Italiano, v. XV. Torino, Utet, 1968.

. "In pari causa turpitudinis", artigo publicado na Rivista di Diritto Civile, Parte seconda, Cedam Casa Editrice Dott. Antonio Milani, Padova, 1966, anno XII.

RIPERT et TEISSEIRE. "Essai d'une théorie de l'enrichissement sans cause en Droit Civil français", Rev. Trim. Dr. Civ., 1904.

RODRlGUES, Silvio. Direito Civil, $2^{\circ}$ v., Das obrigações, $2^{a}$ edição, Editor Max Limonad, 1965.

RUSCHEL, Carlos Maria. "Da repetição do indébito no enriquecimento ilegítimo" Revista Jurídica, v. 1, ano I, jan/fev., 1953.

WETTER, Van. Cours de Droit Romain, II, § 480, 2ª edição, 1876. 